\title{
Abstracts
}

\section{The Law and Elderly People}

Ian Purvis

Ruth Lavery and Laura Lundy, The Social Security Appointee System, Journal of Social Welfare and Family Law, 3 ( 1 994), 3 1 3-327.

In this article the authors analyse the operation of the United Kingdom Social Security Appointee System and seek to evaluate it from the point of view of the claimant, the appointee and the public. Although the background research for the article focused on the Northern Ireland system this is in fact identical to that operated in Great Britain. The existing criteria of appointment and the proposals to be found in the Law Commission Consultation Paper Number 128 are examined. Discussion follows of the current processes for determining incapacity and as regards the choice of appointee and some suggestions are made for reform in both these areas. Criticism is made of Law Commission proposals to widen the scope of the appointee system and it is suggested that the correct process before an appointment is made is at least as important as a procedure which monitors it afterwards. The importance of having a well-informed appointee is also stressed.

A valuable part of the article relates to the whole question of monitoring appointments made under this system. The current legislation does not provide for regular reviews of appointments and an appointment will indeed only be reviewed if a Social Security Officer receives information which suggests that an appointee is not fulfilling their duties. Although the Law Commission had proposed that appointments should be automatically reviewed and that all appointees should be required to agree to provide accounts which show how monies have been spent, the authors contend that these proposals might not be altogether appropriate.

\section{COMMENT}

As a lawyer I spend a lot of time talking to other lawyers about Enduring Powers of Attorney and Receivership in the context of the handling of the finances of those who no longer have the mental capacity to do so for themselves. In practice by far the greater number of elderly confused people with such problems have their benefits 
collected on their behalf under the Social Security Appointee System in respect of which it is acknowledged there is a lack of safeguards for the claimant and the public. At the time of writing we await the final Report of the Law Commission in this area of the law: it has certainly been helpful to have discussion of the Law Commission's earlier proposals enlightened by this article which seeks to indicate what is actually happening on the ground.

\section{Stephen Cragg, Public law for the disadvantaged, Legal Action, April} 1994, 8.

In this brief but important article the author, a solicitor at the Public Law Project, outlines its work and, in particular, its casework strategy. The Public Law Project is a registered charity established in $199^{\circ}$ with the aim of improving access to public law remedies, such as judicial review for people otherwise restricted by poverty, discrimination or some other form of disadvantage. The point is made that whilst public bodies have considerable resources and expertise to defend their decision-making there is a shortage of support for individuals or groups who suffer most from maladministration, unfair procedures and abuse of power.

The project has concentrated on three priorities of which the first is preventative and aims to improve the quality of public decisionmaking with proper mechanisms therefor. The project seeks also to improve the accountability of public decision-making including an increase in the provision of proper reasons for decisions. The third priority of the project is simply 'improving access to justice'. It is the aim of the project to remove the procedural and social obstacles to access to the courts and to explore the potential for greater use of judicial review in cases where it is clearly under-used. The project is able to take on cases, usually for judicial review, on behalf of disadvantaged individuals and groups and while it can not underwrite any litigation costs it will be possible to apply for legal aid or to act without charge in appropriate cases. Among the categories of cases in which the project is particularly interested are those which fall in areas where the full potential of judicial review has not yet been explored, of which examples include provision and regulation of the health service, care in the community and environmental law.

The project, we are told, has launched an initiative with I 5 national charities representing disabled people and carers to investigate the use of public law test cases in the field of care in the community. Stephen 
Cragg argues that it is important that jurisprudence develops in a way that will be of most use to the users of the community care services. The article also outlines other particular areas of interest to the project and the non-casework consultancy services which it is able to supply.

\section{COMMENT}

It is useful to know of the work of the Public Law Project concerning the judicial review of decision-making in relation to the health service and care in the community and it has already begun to make its mark in this field. The Public Law Project can be contacted at Charles Clore House, I 7 Russell Square, London WC $\mathrm{W}_{1}$ B 5 DR. Tel. or 7 I-436 og64.

Age Concern England,

London

\section{Ageing and the Family in Australia John McCormack}

International Year of the Family, Australian Journal on Ageing, Special issue, 13, 4 (1994), I 53-201.

To commemorate 1994 as the International Year of the Family (IYF), the Australian fournal on Ageing $(A J A)$ published this special issue to highlight ageing in the context of the family. The issue begins with a feature article which reviews Australian research and knowledge on ageing and families. It has four sections, each with two or three papers, addressing various ageing and family issues: elder-care, marriage and family support, women's issues in Asia, and the dynamics of caregiving.

The feature article by Kendig on Australian research achievements in ageing and family issues reviews publications listed in the Australian Ageing Research Directory, the $A \mathcal{F} A$, and the Proceedings of the Australian Association of Gerontology. This review shows that publications in the topic emerged in the I950s and that listings in the Directory alone have grown to more than fifty in I 993 , with the majority of these concerning caregiving. The Ageing and the Family project carried out at the Australian National University during $1980-5$ was a landmark study and found, among other things, that older people are characterised more by their diversity and family contributions than by dependence. Kendig reviews the findings under several themes. On care-giving, the findings are similar to those overseas, especially in relation to the key role of daughters and the adverse effects of care-giver stress. On social 